\title{
Anchoring Knowledge in Business-Process Models to support Interoperability of Virtual Organizations Report Workshop 1/Workgroup 2
}

\author{
Peter Heisig ${ }^{1}$, (Ed.), Martine Callot ${ }^{2}$, Jan Goossenaerts ${ }^{3}$, Kurt Kosanke ${ }^{4}$, \\ John Krogstie ${ }^{5}$, and Nenad Stojanovic ${ }^{6}$ \\ ${ }^{\prime}$ FhG-IPK, Germany, ${ }^{2}$ EADS, France, ${ }^{3}$ Eindhoven Univ. of Technology, Netherlands, \\ ${ }^{4}$ CIMOSA Association, Germany, ${ }^{5}$ SINTEF, Norway, ${ }^{6}$ University Karlsruhe, Germany \\ Peter.Heisig@ipk.fhg.de
}

Abstract: $\quad$ see Quad Chart on page 2

The only function of knowledge is to enable right decisions (Chinese wisdom - Neo-Mohism about 200 BC)

\section{INTRODUCTION}

With the emphasis shifting to global markets and inter-organizational cooperation, complexity of enterprise systems is further increasing and with it the importance of real time information and knowledge for decision support. In these complex relationships management acting and reacting must be based on a blend of relevant knowledge and up-to-date information. It is this need for information that becomes of paramount importance in the decisionmaking processes at all management levels of inter-organisational enterprises.

The following Quad-Chart (Table 1) summarises the work of the group that addressed those requirements. It identifies the approach taken to resolve the issues and proposes a concept for integrating the KM and BPM technologies and ideas for future work for testing and enhancing the proposed solutions. 


\subsection{Background on Knowledge Management}

The concept of knowledge management has been used in different disciplines, previously mostly in knowledge management and engineering (Skyrme, Amidon, 1997, De Hoog, 1997, Schreiber, et al. 2000) and artificial intelligence (Göbler, 1992, Forkel, 1994).

Table 1: Working Group Quad-Chart

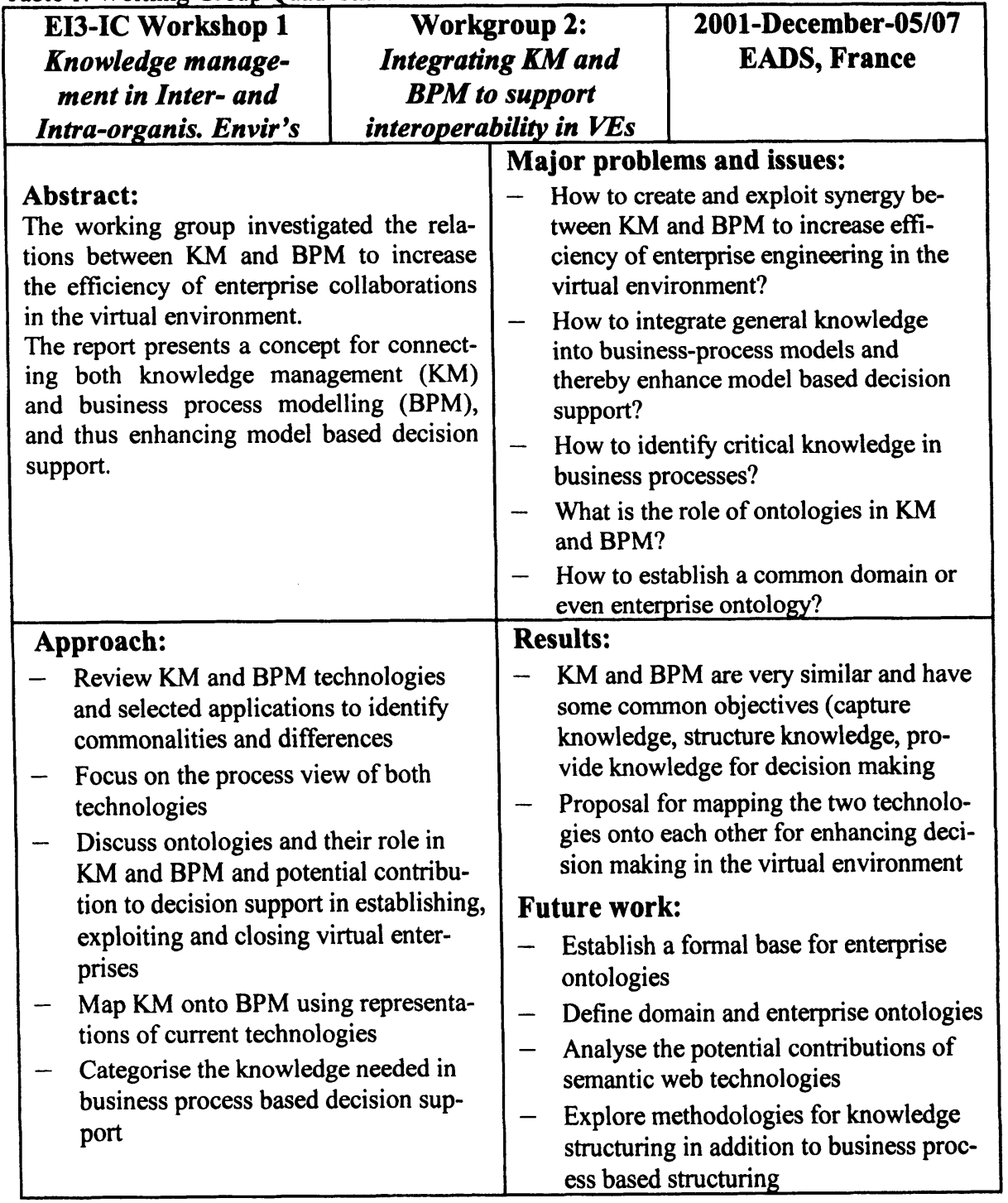

IT-based approaches towards knowledge management are dominant. However, knowledge management is mainly understood by practitioners 
from manufacturing and the service industry as part of corporate culture and a business-oriented method as "The sum of procedures to generate, store, distribute and apply knowledge to achieve organizational goals".

All approaches to knowledge management emphasise the process character with inter-linked tasks or activities. The wording and the number of knowledge management tasks mentioned by each approach differ markedly. They extend from the four activities mentioned above to an approach in Germany with eight building blocks: Identify, Acquire, Develop, Share, Utilise, Render, Assess and Manage knowledge and knowledge goals. The close relationship between processes and knowledge management is underscored by the feedback from companies identifying the design of structures and processes as a critical factor for the success of knowledge management, indicating their focus on the core competence business processes to implement knowledge management.

\subsection{Background on Business Process Modelling}

Business process modelling is usually done for very specific goals, which partly explains the great diversity of approaches found in literature (Vernadat, 1996) and practice. The main reasons for doing BPM are:

a) To improve human understanding and communication: to make sense of aspects of an enterprise and communicate with other people

b) To guide system development

c) To provide computer-assisted analysis through simulation or deduction

d) To enable model deployment and activation for decision making and operation monitoring and control

A number of modelling frameworks have been developed (e.g. ARIS, CIMOSA, GRAI, IEM, PERA) that provide business process modelling languages allowing description of business processes with various degrees of details and for different points of view on the process itself. The GERAM framework work developed by the IFAC/IFIP Task Force (Bernus, et al, 1996) has become the base for international and European standards (pre EN ISO 19439, 2002). The work is still in progress.

The major application area of BPM is still Business-Process Reengineering (BPR) and Business-Process Optimisation. The real potential of BPM real time decision support - is barely exploited.

\subsection{Background on Ontologies}

The task of the ontologist is described as: "to recognise, analyse and interrelate those concepts enabling him to produce a unified picture of reality" (Bunge, 1977). With reality understood as being the concrete world, but not 
including the concepts that words may designate. Ontology joins the natural and social sciences as a discipline concerned with concrete objects. It has the task to construct the most general theories concerning these concrete objects, their being and becoming. In contrast, common "scientific" knowledge domains such as ergonomics, logistics and many others, each define concepts and relationships, and connect them to some area of investigation. Whereas the practitioner of a discipline has a strong awareness of the concrete-world things as the anchors and purposes of the analysis, the heavy conceptual bias of the knowledge engineer or information analyst has given rise to several so-called ontologies, which are void of the being and becoming of the object of study.

Focussed ontologies have been defined and used in several domains including medicine, chemistry, and legal knowledge representation. In the area of enterprise modelling, early work that would nowadays be classified under the name enterprise ontology is the REA Accounting Model (McCarthy, 1982). Quite a few "enterprise" ontologies do not emphasise the distinction between things and their changes on the one hand and concepts on the other hand. These ontologies therefore have more fundamental concepts than strictly necessary. Examples are the Enterprise Ontology project (Ushold, et al, 1998) and TOVE (Toronto Ontology for Virtual Enterprise) (Fox, et al, 1998).

\section{APPROACHES TO INTEGRATE KM AND BPM}

Both $\mathrm{KM}$ and BPM aim at improving the results of the organisation, delivering a product or/and service to a client. The related business processes use knowledge as a resource. Nevertheless, only very few approaches to knowledge management have explicitly acknowledged this relation. And even fewer approaches have tried to develop a systematic method to integrate knowledge management activities into the business processes. Three forms of KM-BPM integration can be found (Mueller, et al, 2001):

a) BPM as the basis for the knowledge management is based on treating knowledge management as a specific business process in which an organisation creates and uses individual and collective knowledge (Macintosh et al, 1998, Mentzas, Apostolou, 1998).

b) $\mathrm{KM}$ as a basis for the Business-Process Improvement/Reengineering can provide knowledge for modelling, optimisation and automation of business processes.

c) $\mathrm{KM}$ integrated in the process- or workflow-management systems to provide access to the knowledge that is relevant for the current task. 
In this paper we focus on the last form since it is the most reliable approach for integrating KM and BPM in the virtual organisation.

Following is a list of selected approaches:

- CommonKADS methodology (Schreiber, et al, 2000) integrates an organizational model, critical success factors and the KM cycle with seven activities: Identify, plan, acquire and/or develop, distribute, foster the application, control and maintain, dispose.

- Business KM (Bach, et al, 1999) tries to relate KM activities to business objects and business processes. The approach distinguishes between business processes, the knowledge structure, and the knowledge base.

- Knowledge value chain approach (Weggeman, 1999) is a continuously repeated process, which is composed of six KM tasks on the operational level: identify, document, develop, share, apply and evaluate knowledge.

- Model-based KM approach (Allweyer, 1998) adds a new perspective especially for knowledge-intensive processes (less structured, not exactly foreseeable and, in most cases, not repeatable).

- Reference-model for KM (Warnecke, et al, 1998) is an approach of a model-based design of knowledge-oriented processes for $\mathrm{KM}$. The reference model consists of an object model with system elements and activities (identify, make explicit, distribute, apply and store), a process model and an implementation model.

- Process KM (Jorgenson, Carlsen, 1999, Jorgensen, 2000) is defined as the collection of processes necessary for innovation, dissemination, and exploitation of knowledge in a co-operating ensemble where knowledge seekers are linked to knowledge sources and a shared knowledge base is cultivated.

\section{PROPOSAL FOR INTEGRATING KM AND BPM}

\subsection{Assumptions and approach}

Our approach to business process oriented knowledge management is based on the following assumptions:

- KM operative methods and procedures used to generate, store, distribute and apply knowledge have to be integrated and oriented towards particular business processes. 
- KM has to consider the specific cultural conditions - the network of different professional cultures, functional cultures and underlying corporate traditions and values (Davenport, et al, 1996).

- KM has to accommodate the daily use of knowledge and know-how of our colleagues, suppliers, clients, competitors and other resources (Hansen, et al, 1999).

- The drivers for both the traditional business processes and the knowledge management processes are combined to fulfil the business needs (Bullinger, et al, 1997).

Our approach rests on identifying relations between KM and BPM, using the IPK approach on Knowledge Management shown in Fig. 1 (Heisig, 2001) and the Enterprise Modelling Framework identified by (pre EN/ISO 19439, 2002) and partly shown in Fig. 2. Business process related knowledge is being captured/generated, stored and applied during all phases of the model life cycle. Such knowledge is used in model-

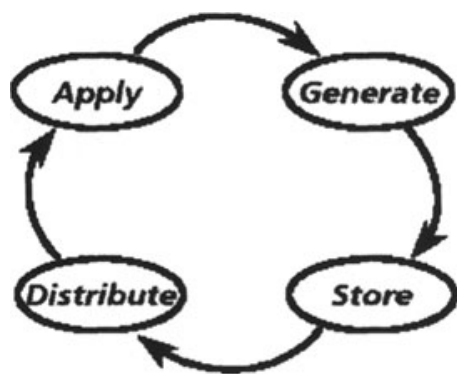

Figure 1: KM activities based enterprise engineering during most of the life cycle phases and is applied for operational use during the enterprise operation phase. Knowledge distribution beyond the area of the business processes is not covered in the modelling framework.

Therefore the KM activity Distribute has to be defined as being applicable during all life cycle phases identified in the modelling framework, providing for authorisations, promotion and exploitation of all the enterprise knowledge. This additional distribution needs might give rise for additional properties of the process model, i.e. meta-data specifically useful for

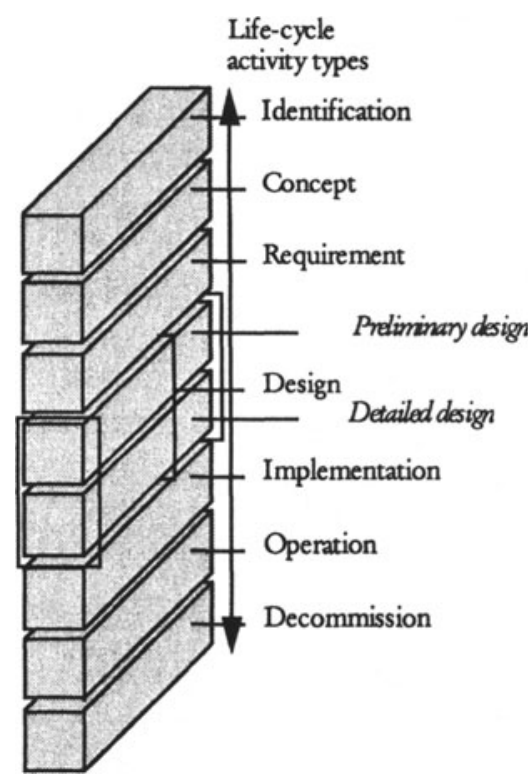

Figure 2: Modelling Framework reuse across the enterprise.

Establishing term (index) mappings between information and knowledge according to the structure of the business process has the advantage that knowledge distribution and application in the business process community is 
significantly improved since this structure is well known and accepted in the enterprise.

\subsection{The role of ontology}

Ontologies are a conceptualisation of a domain (Gruber, 1993). Thus, they provide mechanisms to structure knowledge sources according to the characteristics of the domain. It means that ontologies (or the vocabulary that one ontology provides) can be used for the creation of an indexing system, which is appropriate for the content description of the knowledge sources in order to make the sharing of this knowledge more efficiently (Stabs, et al, 2001). This is achieved by constraining the meaning of some indexes (terms) according to the axioms in the ontology. For example, it is possible to distinguish term chair as an organisational role from the term chair in the context of a business activity where chairs, as furniture, are assembled. Therefore, ontologies provide means for the semantic-based providing and access to knowledge, which is the crucial requirement for an efficient knowledge management system.

In order to anchor knowledge sources to the business processes, one needs two kinds of the indexes and term mappings between them - one index for each knowledge source pertaining to a problem domain (e.g. automobile industry, logistics, or ergonomics) and one index for the knowledge on the business process (e.g. assembling a product). In that way knowledge sources can be applied to each business process for which a mapping has been established. An efficient integration of KM and BPM need two kinds of ontologies: the Domain ontology that describes the knowledge sources of a problem domain (content) and the Enterprise ontology that corresponds to the business processes (creation and application context) (Abecker, et al, 1998).

From the virtual organisation point of view, the role of the ontologies in the knowledge sharing is even more important:

- Different vocabularies, used in geographically distributed organisational units, can be merged on the conceptual level (i.e. not on the syntax level, but on the level of the meaning of the terms) using a Domain ontology;

- Inputs and outputs of the business process can be described on the conceptual level (e.g. an input of a business activity is the Name of the customer, but not any string) using an Enterprise ontology; term (index) mappings existing between the Enterprise ontology and certain Domain ontologies then enable -semantic composition of the processes in a supplier-customer chain 
- The comparison between similar business processes in different organisational units can be performed more accurately when the processes are described on the conceptual level, using an Enterprise ontology or one or another Domain ontology.

The presented arguments confirm the importance of the usage of ontologies in the KM-BPM integration and motivate our further research in this direction.

The PSIM environment (Goossenaerts, Pelletier, 2002) makes the distinction between the physical reality of the enterprise - it's being and becoming (context) - on the one hand, and the concepts and relationships (content) that knowledge domains use to analyse this reality. Within the Organization, which is the subject of various analyses in different knowledge domains, the business-process model serves as the pivotal core for term mapping and translation services in the organisation's knowledge engine. These services allow knowledge from various disciplines to be applied in the analysis of the organisation. The importance of reuse of past experience and solutions in organisational learning also justify anchoring the problem domain ontologies in the physical reality of the assembly operations.

\subsection{Gaps and further work}

Various methods and tools for Business-Process Reengineering (BPR) or Business-Process Optimisation, have been developed by academia and consulting companies. Despite these developments, a comparative study of methods for business process redesign completed by the University St. Gallen, Switzerland (Hess, Brecht, 1995) concludes: , hidden behind a more or less standard concept, there is a multitude of the most diverse methods. A standardised design theory for processes has still not emerged."

Adopting an ontology-based approach, further work must focus on how to define domain and enterprise ontologies and how to express termmappings between the two ontologies. Also the combined application of KM and BPM in enterprise engineering (EE) especially in the area of virtual enterprises needs further investigations. The aim is to explore the relations between knowledge structuring and process structuring. Interoperability of virtual organisations is another area where BPR and EE will benefit from using such an ontology-based approach.

Semantic web technologies seem to have the potential to contribute to application of KM and BPM as well. However, basic research is needed in this area. 


\section{SUMMARY AND CONCLUSIONS}

Knowledge management is currently one of the buzzwords on the agenda of Top-Management and of software providers and consulting companies. Knowledge is regarded as one or even the main factor for private and public organisations to gain competitive advantage.

With business process engineering, companies have focused their attention on eliminating non-value-adding process steps. In the future, companies will regard knowledge management activities as an integral part of their business processes. They will enhance their ability to deploy a significant source of competitive advantage - the know-how and learning of the people.

Behind the buzzword of knowledge management hide essential techniques for the systematic management of knowledge and experiences about operational processes. These techniques will not become superfluous as long as the economy remains dynamic. On the contrary, they will become part of services that add "ease of knowledge application" to the "ease of planning and operation" that has already revolutionised work in organisations.

\section{REFERENCES}

Abecker, A. Bernardi, A. Hinkelmann, K. Kuehn, O. Sintek, M. (1998), Towards a Technology for Organizational Memories. IEEE Intelligent Systems \& Their Applications, 13(3).

Allweyer, Th. (1998), Modellbasiertes Wissensmanagement. In: Information Management, 1. Bach, V. Vogler, P. Österle, H. (Eds.) (1999): Business Knowledge Management. Praxiserfahrungen mit Intranet-basierten Lösungen, Springer-Verlag.

Bernus, P, Nemes, L, Williams, T.J. (Eds.), (1996), Architectures for Enterprise Integration, The findings of the IFAC/IFIP Task Force, Chapman \& Hall.

Bullinger, H.-J. Wörner, K. Prieto, J. (1997), Wissensmanagement heute. Daten, Fakten, Trends, Fraunhofer IAO, Stuttgart.

Bunge, M. (1977), Ontology I: The Furniture of the World. Treatise on Basic Philosophy Vol. 3, Reidel, Boston.

Davenport, Th. H. Jarvenpaa, S.L. Beers, M.C. (1996), Improving Knowledge Work Processes. Sloan Management Review.

De Hoog, R. (1997), CommonKADS: Knowledge Acquisition and Design Support Methodology for Structuring the KBS Integration Process. In: Leibowitz J. Wilcox, L.C. (Eds.), Knowledge Management and Its Integrative Elements. CRC Press, Boca Raton, New York.

F.B. Vernadat, (1996), Enterprise Modelling and Integration, Principles and Applications; Chapman and Hall.

Forkel, M. (1994), Kognitive Werkzeuge - ein Ansatz zur Unterstützung des Problemlösens. Hanser Verlag, München.

Fox, M.S. Barbuceanu, M. Gruninger, M. \& Lin, J. (1998), An Organisation Ontology for Enterprise Modeling. In M. Prietula, K. Carley \& L. Gasser (Eds.), Simulating Organizations: Computational Models of Institutions and Groups, Menlo Park CA: AAAI/MIT Press. 
Göbler, Th. (1992), Modellbasierte Wissensakquisition zur rechnerunterstützten Wissensbereitstellung für den Anwendungsbereich Entwicklung und Konstruktion. Hanser Verlag, München.

Goossenaerts, J.B.M. Pelletier, C. (2002), The PSIM Ontology and Enterprise Modeling. In: Eijnatten van, F.M. (Ed.) Participative Simulation Environment for Integral Manufacturing Enterprise Renewal. TNO, Arbeid, Amsterdam, The Netherlands (forthcoming).

Gruber, T. R. (1993), A Translation Approach to Portable Ontology Specifications. Knowledge Acquisition, 5(2).

Hansen, M.T. Nohria, N. Tierney, T. (1999), What's your Strategy for Knowledge Management. In: Harvard Business Review, March-April.

Heisig, P. (2001), Business Process Oriented Knowledge Management. In: Kai Mertins, Peter Heisig, Jens Vorbeck (Eds.): Knowledge Management. Best Practices in Europe, SpringerVerlag.

Hess, Th. Brecht, L. (1995), State of the Art des Business Process Redesign. Darstellung und Vergleich bestehender Methoden. Gabler, Wiesbaden, Germany.

Jørgensen, H. D. (2000), Software Process Model Reuse and Learning, in Proceedings of Process Support for Distributed Team-based Software Development (PDTSD'00), Orlando, Florida. IIIS - International Institute of Informatics and Systemics.

Jørgensen, H. D. Carlsen, S. (1999), Emergent Workflow: Integrated Planning and Performance of Process Instances, Workflow Management '99, Münster, Germany.

Macintosh, A. Filby, I. \& Tate, A. (1998), Knowledge Asset Road Maps. In Proceedings of The Second International Conference on Practical Aspects of Knowledge Management (PKM98), 29-30 October, Basel, Switzerland.

Mentzas, G. and Apostolou, D. (1998), Towards a Holistic Knowledge Leveraging Infrastructure: The KNOWNET Approach, Proc. Second International Conference on Practical Aspects of Knowledge Management, 29-30 October, Basel, Switzerland.

McCarthy, W.E. (1982), The REA Accounting Model: A Generalized Framework for Accounting Systems in a Shared Data Environment. The Accounting Review, Vol. LVII(3).

Mueller, H. J. Abecker, A. Maus, H. Hinkelmann, K. (2001), Software-Unterstützung für das Geschäftsprozessorientierte Wissensmanagement. In Proceedings des Workshops Geschäftsprozessorientiertes Wissensmanagement anlässlich der WM'2001 in BadenBaden.

Pre EN/ISO 19439, (2002), Enterprise integration - Framework for enterprise modelling, CEN TC 310, WG1.

Schreiber A. Th. Hoog, R. Akkermans, H. Anjewierden, A. Shadbolt, N. Velde W. (2000), Knowledge Engineering and Management. The CommonKADS Methodology. The MIT Press.

Skyrme, D.J. Amidon, D.M. (1997), Creating the Knowledge-Based Business. Business Intelligence, London, New York

Staab, S. Schnurr, H.-P. Studer, R. Sure, Y. (2001), Knowledge Processes and Ontologies. IEEE Intelligent Systems. 16(1), Special Issue on Knowledge Management.

Uschold, W. King, M. Moralee, S. \& Zorgios, Y. (1998), The Enterprise Ontology. The Knowledge Engineering Review, 13, Special Issue on Putting Ontologies to Use.

Warnecke, G. Gissler, A. Stammwitz, G. (1998), Referenzmodell Wissensmanagement - Ein Ansatz zur modellbasierten Gestaltung wissensorientierter Prozesse. Information Management 1 .

Weggeman, M. (1999), Kenntnismanagement. Inrichtigen besturing van kennisintensieve organisaties. Scriptum, Schiedom German: Wissensmanagement - Der richtige Umgang mit der wichtigsten Ressource des Unternehmens. MITP-Verlag, Bonn, Germany. 